\title{
Matrix metalloproteinase 9 and cellular fibronectin plasma concentrations are predictors of the composite endpoint of length of stay and death in the intensive care unit after severe traumatic brain injury
}

Jean-Christophe Copin ${ }^{1,2,3,6^{*}}$, Marie My Lien Rebetez ${ }^{4}$, Natacha Turck ${ }^{5}$, Xavier Robin ${ }^{5}$, Jean-Charles Sanchez ${ }^{5}$, Karl Schaller ${ }^{5}$ Yvan Gasche ${ }^{1,2}$ and Bernhard Walder ${ }^{4}$

\begin{abstract}
Background: The relationship between severe traumatic brain injury (TBI) and blood levels of matrix metalloproteinase-9 (MMP-9) or cellular fibronectin (c-Fn) has never been reported. In this study, we aimed to assess whether plasma concentrations of MMP-9 and c-Fn could have predictive values for the composite endpoint of intensive care unit (ICU) length of stay (LOS) of survivors and mortality after severe TBI. Secondary outcomes were the state of consciousness measured with the Glasgow Coma Scale (GCS) of survivors at 14 days and Glasgow Outcome Scale Extended (GOSE) at 3 months.

Methods: Forty-nine patients with abbreviated injury scores of the head region $\geq 4$ were included. Blood was sampled at 6, 12, 24 and 48 hours after injury. MMP-9 and c-Fn concentrations were measured by ELISA. The values of MMP-9 and C-Fn, and, for comparison, the value of the GCS on the field of the accident (fGCS), as predictors of the composite outcome of ICU LOS and death were assessed by logistic regression.

Results: There was a linear relationship between maximal MMP-9 concentration, measured during the 6-12-hour period, and maximal c-Fn concentration, measured during the 24-48-hour period. The risk of staying longer than 9 days in the ICU or of dying was increased in patients with a maximal early MMP-9 concentration $\geq 21.6 \mathrm{ng} / \mathrm{ml}$ $(\mathrm{OR}=5.0 ; 95 \% \mathrm{Cl}: 1.3$ to $18.6 ; \mathrm{p}=0.02)$ or with a maximal late c-Fn concentration $\geq 7.7 \mu \mathrm{g} / \mathrm{ml}(\mathrm{OR}=5.4 ; 95 \%$ $C l: 1.4$ to 20.8; $p=0.01)$. A similar risk association was observed with $f G C S \leq 8(O R, 4.4 ; 95 \% C l, 1.2-15.8 ; p=0.02)$. No relationship was observed between MMP-9, c-Fn concentrations or fGCS and the GCS at 14 days of survivors and GOSE at 3 months.
\end{abstract}

Conclusions: Plasma MMP-9 and c-Fn concentrations in the first 48 hours after injury are predictive for the composite endpoint of ICU LOS and death after severe TBI but not for consciousness at 14 days and outcome at 3 months.

Keywords: Head injury, Prediction, Outcome, Plasmatic biomarker

\footnotetext{
* Correspondence: jean-christophe.copin@unige.ch

${ }^{1}$ Geneva Neuroscience Center, University of Geneva, Geneva, Switzerland

${ }^{2}$ Division of Intensive Care, University Hospitals of Geneva, Geneva,

Switzerland

Full list of author information is available at the end of the article
} 


\section{Background}

The personal and societal consequences of severe traumatic brain injury (TBI) are considerable related to its high rate of occurrence of cognitive dysfunction and disability [1,2]. Its estimated incidence in Europe is between 9-17 per 100'000 person/year [3,4]. The majority of patients are men with a mean age of 40 to 50 years, injured by falls or road traffic accidents [5,6]. The outcome after severe TBI is often unfavorable with one third to one half of patients dying during the 6 following months and one third presenting severe disabilities [6-8]. In recent years validated models were developed to predict poor outcome after TBI [9]. However, predictive power when using such clinical models for individual patients is still limited. All these models use components of the Glasgow Coma Scale (GCS) which is known to have a large inter-individual assessment range [10] and which may explain this limited prediction capacity for individual patients. One research direction in patients with TBI is the attempt to improve these clinical prediction models and to improve overall management via new diagnostic assessments. Neuronal, glial and inflammatory biomarkers were tested to add supplementary information on diagnosis and to provide early information about prognosis on functional and cognitive outcome [11-18]. Among all these biomarkers, S100b, a calcium binding protein with high expression in astrocytes, has been the most extensively investigated. S100b levels predicted mortality or poor outcome $[11,19]$.

Matrix metalloproteinases (MMP) are a family of zincdependent endopeptidases involved in a number of neurological diseases, in which neuroinflammation plays a significant role [20]. MMP-9 degrades components of the basal lamina, such as fibronectin and collagen-IV, leading to disruption of the blood-brain barrier and vasogenic brain edema [21-23]. Elevated brain MMP-9 concentration was found in experimental TBI [24-26] and brain lesion volumes were significantly reduced in TBI animals after overexpression of tissue inhibitor of metallaloproteinases-1 or genetic knocked-out of the mmp-9 gene $[27,28]$. Recently, it was described an acute elevation of MMP-9 concentration in the cerebrospinal fluid of six severe TBI patients as compared to normal pressure hydrocephalus patients, but no differences in plasma concentration between these two groups of patients were observed [29]. Two other studies, carried out on a limited number of patients, showed elevated MMP-9 concentration in the plasma [30,31] and in the brain extracellular fluid [31] during the acute stage of TBI.

Fibronectins are adhesive glycoproteins that promote cell-cell and cell-matrix interactions [32]. Two forms of fibronectins exist: plasma fibronectin, a dimeric and soluble form secreted by hepatocytes directly into the circulation, and cellular fibronectin (c-Fn), a multimeric form assembled into fibrils and found in the extracellular matrix [33]. Because c-Fn is incorporated between endothelial cells and pericytes [34], high plasma levels of this molecule in TBI patients might be indicative of the loss of blood brain barrier integrity. Elevated concentrations of c-Fn were detected in the plasma after major abdominal, thoracic or pulmonary traumatic injury [35]. However, to our knowledge, no study has reported the release of c-Fn into the circulation after TBI.

Blood levels of MMP-9 and c-Fn have good predictive values for the evaluation of hemorrhagic transformation after thrombolytic therapy in acute ischemic stroke [36]. However, the relationship between TBI outcome and blood levels of MMP-9 and c-Fn has never been reported. In this study, we investigated the hypothesis that plasma MMP-9 and c-Fn concentrations could play also a role in TBI patients in the early period after injury, and, in particular, could have a predictive value for certain outcomes such as intensive care unit (ICU) length of stay (LOS) and mortality after severe TBI.

\section{Methods}

\section{Patients}

We analysed the data of consecutive patients enrolled in a prospective study on "Patient-relevant Endpoints after Brain Injury from Traumatic Accidents" between May 2007 and November 2009. The study was approved by the ethical committee of the Geneva University Hospital, Geneva, Switzerland and was a follow up investigation of our previous study [8]. Written informed consent by proxy within 14 days after injury replaced informed consent by patients, who were all severely injured at the time of enrolment.

Patients with TBI from blunt trauma were enrolled and included if severe TBI was confirmed by cerebral CT scan. Severe TBI was defined by the presence of an abbreviated injury scores (AIS) of the head region (HAIS) $\geq 4$ within the first 24 hours (first cerebral CT or following CT within 24 hours after injury). For AIS assessment, we used the 1990 revision, update 1998 [37]. On the 6-point scale of AIS, values of 4 to 6 correspond to severe to fatal lesions.

\section{Outcomes}

The primary outcome was the composite endpoint ICU LOS for survivors and mortality in the ICU.

Secondary outcomes included ICU LOS for survivors, mortality before 3 months, the state of consciousness (Glasgow Coma Scale) at 14 days (GCS $>8=$ conscious) and Glasgow Outcome Scale Extended (GOSE) at 3 months [38]. Contrary to the hospital LOS where readiness of discharge and real discharge may be different, patients always left the ICU without delay; i.e. when their 
medical conditions permitted them to be discharged. Therefore, this ICU LOS as endpoint was investigated.

\section{Predictive factors}

The relationships between the potential predictive factors MMP-9, c-Fn and the established predictive factor GCS on the field of the accident (fGCS), as reported by out of hospital emergency medical services were assessed [39].

In addition, other early clinical and radiological parameters such as cerebral edema, midline shift, subarachnoid hemorrhage (SAH), intraventricular hemorrhage (IVH) or abnormal pupil reactions on the field of the accident were assessed.

\section{MMP-9 and c-Fn enzyme-linked immunosorbent assays}

Blood was sampled at 6, 12, 24 and 48 hours after injury in EDTA tubes and centrifuged. Plasma was stored at $-80^{\circ} \mathrm{C}$ until analysis. Plasma MMP-9 and c-Fn concentrations were measured blindly by enzyme-linked immunosorbent assays (biotrack Elisa system, Amersham \#RPN2614; Elisa kit for human c-Fn, Biohit Oyj \#603010) according to the manufacturer's instructions.

\section{Statistical analysis}

Data were expressed as medians (interquartile ranges). Boxplots show median values, lower and upper quartiles, and the largest and smallest observed values (whiskers) if the values lay within 2.5 time the interquartile range. Multiple group comparisons of related samples were done using the Friedman's 2-Way ANOVA by Ranks test followed by Wilcoxon Matched-Pair Signed-Rank tests. Independent samples were compared using the MannWhitney $\mathrm{U}$ test for 2 samples. Linear regression was used to assess the relationship between MMP-9 and c-Fn concentrations. Receiver operating characteristic (ROC) curves and logistic regression were used to assess the values of MMP-9, c-Fn and fGCS as predictors of prolonged ICU stay or death and to determine odds ratios (OR) and sensitivity/specificity. Statistical analyses were performed with PASW Statistics release 18 for the Macintosh. $\mathrm{P}<0.05$ was considered significant. ROC curve analyses were performed with the pROC package for TIBCO Spotfire S+ version 8.2 for Windows. Comparison between paired ROC curves were computed with the bootstrap test and 10000 replicates as described previously [40].

\section{Results}

Clinical characteristics of the cohort and outcome

Forty-nine patients were included (13 patients (27\%) with a HAIS of 4 and 36 patients (73\%) with a HAIS of 5). The median fGCS was 7 (3-10) and $40.0 \%$ of the patients had abnormal pupil reaction (Table 1). The median age of the cohort was 39 years (26-55). Six patients
Table 1 Clinical characteristics of the cohort

\begin{tabular}{lcc}
\hline Characteristics of the cohort & Values & $\mathbf{n}$ \\
\hline Age (years) & $39(25-55)$ & 49 \\
Height (m) & $1.75(1.70-1.80)$ & 29 \\
Weight (kg) & $70(66-80)$ & 31 \\
GCS on scene & $7.0(3.0-10.0)$ & 49 \\
Abnormal pupil reaction on scene & $18 / 45(40.0 \%)$ & 45 \\
Alcohol smell & $15 / 46(32.6 \%)$ & 46 \\
Intubation on scene & $38 / 49(77.6 \%)$ & 49 \\
GCS in emergency department & $3.0(3.0-3.0)$ & 46 \\
Abnormal pupil reaction in & $18 / 46(39.1 \%)$ & 46 \\
emergency department & & \\
SAPS II & $52.0(44.5-56.5)$ & 39 \\
ISS & $29(25-34)$ & 49 \\
Mortality at 14 days & $11 / 49(22.4 \%)$ & 49 \\
GCS at 14 days & $11.0(3.0-15.0)$ & 49 \\
GCS of survivors at 14 days & $13.5(8.0-15.0)$ & 38 \\
Abnormal pupil reaction of & $4 / 34(11.8 \%)$ & 34 \\
survivors at 14 days & & \\
Mortality at 3 months & $15 / 49(30.6 \%)$ & 49 \\
GOSE at 3 months & $3.0(1.0-4.0)$ & 37 \\
GOSE of survivors at 3 months & $3.5(3.0-4.0)$ & 22 \\
LOS of survivors in ICU (days) & $9.0(4.0-15.0)$ & 37 \\
LOS of survivors in acute hospital (days) & $15.5(10.0-24.5)$ & 36 \\
\hline
\end{tabular}

(12\%) had multiple traumas with an AIS of the chest region of 4 (5 patients: 4 died, 1 survived) or an AIS of the abdomen region of 4 ( 1 patient who survived).

The median ICU LOS of the survivors was 9.0 days (4.0-15.0); median hospital LOS was 15.5 days (10.024.5). Fifteen patients (30.6\%) died before 3 months. The median GCS of the survivors at 14 days was 13.5 (8-15). The median GOSE of the survivors at 3 month was $3.5(3-4)$.

\section{Temporal profiles of plasma MMP-9 and c-Fn concentrations}

Six hours after TBI, plasma MMP-9 concentration was $25.9 \mathrm{ng} / \mathrm{ml}$ (9.8-60.1) (Table 2). MMP-9 concentration decreased significantly over the next days, to reach a final value of $6.4 \mathrm{ng} / \mathrm{ml}(1.4-19.3) 48$ hours after injury $(p=0.0008)$.

\begin{tabular}{lccccc}
\multicolumn{6}{l}{ Table 2 Plasma MMP-9 and c-Fn concentrations } \\
\hline $\begin{array}{l}\text { Time after } \\
\text { TBI (h) }\end{array}$ & $\begin{array}{l}\text { MMP-9 } \\
(\mathbf{n g} / \mathbf{m l})\end{array}$ & $\mathbf{P} *$ & $\begin{array}{c}\mathbf{c - F n} \\
(\boldsymbol{\mu} \mathbf{g} / \mathbf{m l})\end{array}$ & $\mathbf{P}^{*}$ & $\mathbf{n}$ \\
\hline 6 & $25.9(9.8-60.1)$ & & $3.3(2.4-6.1)$ & & 26 \\
12 & $16.1(7.8-31.2)$ & 0.01 & $4.4(2.6-6.3)$ & 0.17 & 40 \\
24 & $9.3(5.2-20.0)$ & 0.02 & $5.3(2.7-8.5)$ & 0.0001 & 45 \\
48 & $6.4(1.4-19.3)$ & 0.0008 & $5.3(3.5-9.3)$ & 0.005 & 35 \\
\hline
\end{tabular}

* As compared to the 6-hour time point. 
Six hours after TBI, plasma c-Fn concentration was $3.3 \mu \mathrm{g} / \mathrm{ml}$ (2.4-6.1) (Table 2). c-Fn concentration increased significantly over the next days, to reach a final value of $5.3 \mu \mathrm{g} / \mathrm{ml}(3.5-9.3) 48$ hours after injury $(p=0.005)$.

There was a linear relationship between maximal MMP-9 concentration measured between 6 and 12 hours and maximal c-Fn concentration measured between 24 and 48 hours (Figure 1). The higher the MMP9 concentration between 6 and 12 hours, the higher the subsequent c-Fn concentration between 24 and 48 hours $(\mathrm{r}=0.310, n=40, p=0.05)$. Moreover, by grouping patients according to maximal MMP-9 concentration between 6 and 12 hours, we observed a c-Fn concentration increase over the first 48 hours only in patients with an early MMP-9 concentration $\geq 20 \mathrm{ng} / \mathrm{ml}$ (Figure 2 ).

\section{Relationship between the potential predictive factors} MMP-9 and c-Fn and the established predictive factor f GCS A trend toward higher maximal early MMP-9 concentration $(+42 \%, p=0.13, n=43)$ or maximal late c-Fn concentration $(+83 \%, p=0.10, n=46)$ was observed in patients with a fGCS $\leq 8$ as compared to patients with a fGCS $>8$ (Table 3).

\section{Relationship between MMP-9, c-Fn, f GCS and early clinical and radiological parameters}

Significantly lower fGCS and a trend toward higher maximal early MMP-9 concentration or late c-Fn concentration were observed in patients with edema, with SAH or with abnormal pupil reactions on the field of

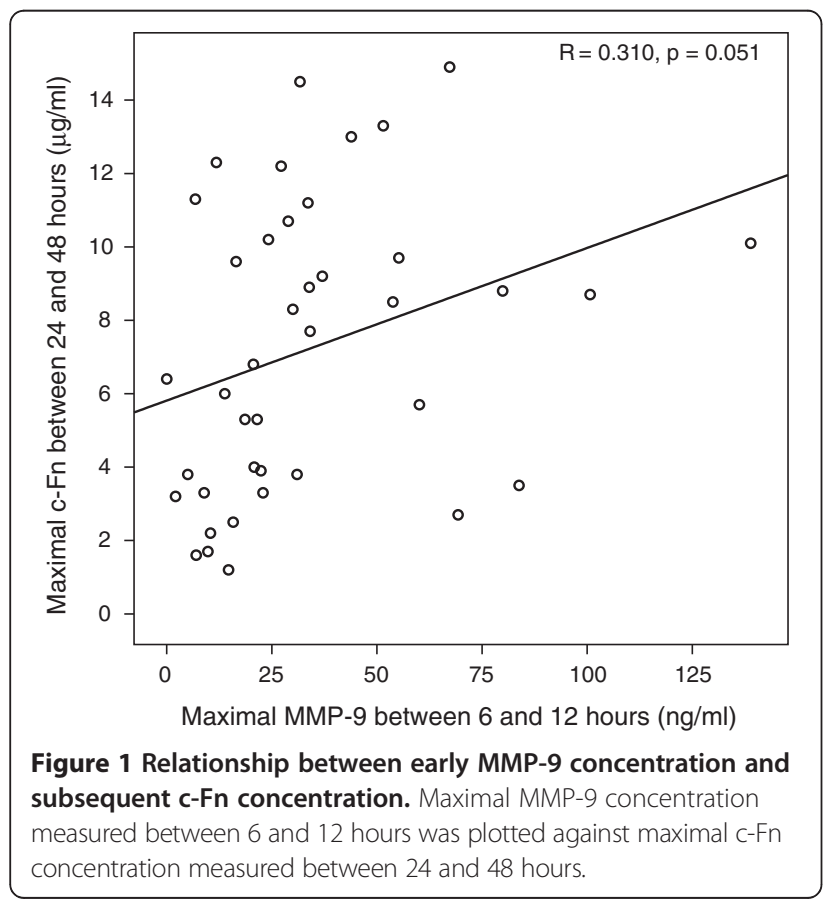

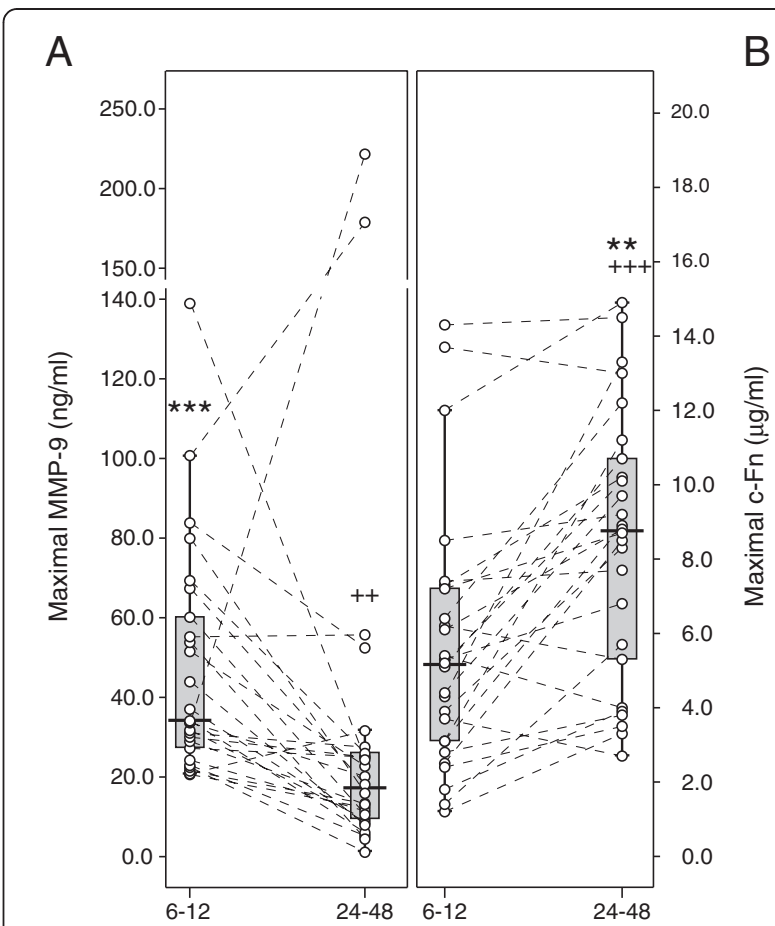

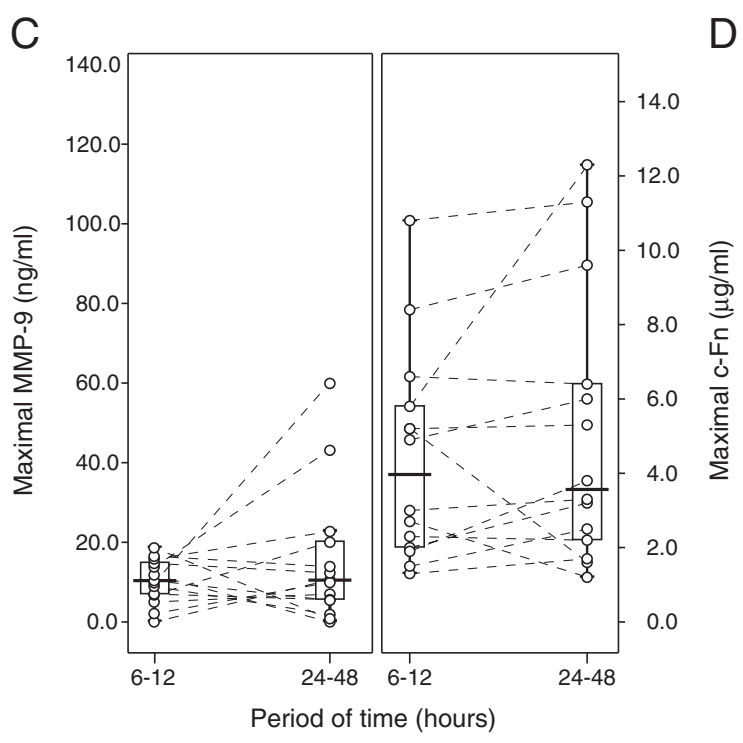

Figure 2 Variations of MMP-9 and c-Fn concentrations during the $\mathbf{4 8}$ hours following TBI. Patients were grouped according to the maximal MMP-9 concentration between 6 and 12 hours. Grey boxplots: group of patients with maximal early MMP-9 concentration $\geq 20 \mathrm{ng} / \mathrm{ml}$, white boxplots: group of patients with maximal early MMP-9 concentration $<20 \mathrm{ng} / \mathrm{ml}$. A and C: maximal MMP-9 concentration between 6 and 12 hours, B and D: maximal c-Fn concentration between 24 and 48 hours. Each line represents a single patient. ${ }^{* *} p<0.01,{ }^{* * *} p<0.001$ as compared to the opposite group of patients at the same period. $++p<0.01,+++p<0.001$ as compared to the $6-12$ hour period within the same group. 
Table 3 Relationship between MMP-9, c-Fn or fGCS and different clinical parameters

\begin{tabular}{|c|c|c|c|c|c|c|c|c|c|c|}
\hline \multirow[t]{2}{*}{ Parameters } & & \multicolumn{3}{|c|}{$\begin{array}{c}\text { Maximal MMP-9 } \\
\text { between 6-12 hours }\end{array}$} & \multicolumn{3}{|c|}{$\begin{array}{c}\text { Maximal c-Fn } \\
\text { between 24-48 hours }\end{array}$} & \multicolumn{3}{|c|}{ fGCS } \\
\hline & & $\mathrm{ng} / \mathrm{ml}$ & $P$ & $n$ & $\mu \mathrm{g} / \mathrm{ml}$ & $P$ & $n$ & Score & $P$ & $n$ \\
\hline \multirow[t]{2}{*}{ Oedema } & No & $22.0(11.8-51.5)$ & 0.24 & 22 & $6.0(3.5-8.9)$ & 0.24 & 25 & $8.5(4.0-12.0)$ & 0.007 & 26 \\
\hline & Yes & $31.0(20.6-43.9)$ & & 21 & $8.3(3.9-11.2)$ & & 21 & $4.0(3.0-7.5)$ & & 23 \\
\hline \multirow[t]{2}{*}{ Midline shift (mm) } & $<5$ & $24.2(15.8-55.2)$ & 0.52 & 29 & $6.6(3.8-10.1)$ & 0.64 & 30 & $7.0(4.0-10.0)$ & 0.28 & 33 \\
\hline & $\geq 5$ & $25.9(13.8-34.1)$ & & 14 & $6.9(3.6-10.2)$ & & 16 & $4.0(3.0-8.5)$ & & 16 \\
\hline \multirow[t]{2}{*}{ SAH } & No & $20.8(9.8-34.1)$ & 0.21 & 13 & $4.7(3.0-9.2)$ & 0.26 & 12 & $10.0(6.0-12.0)$ & 0.03 & 13 \\
\hline & Yes & $29.5(16.3-53.8)$ & & 30 & $7.2(3.9-10.2)$ & & 34 & $5.0(3.0-8.5)$ & & 36 \\
\hline \multirow[t]{2}{*}{ IVH } & No & $24.2(13.8-53.8)$ & 0.71 & 33 & $7.6(3.7-10.0)$ & 0.59 & 35 & $7.0(3.0-10.0)$ & 0.99 & 37 \\
\hline & Yes & $25.9(20.8-34.1)$ & & 10 & $4.0(3.9-8.9)$ & & 11 & $5.5(3.0-11.0)$ & & 12 \\
\hline \multirow[t]{2}{*}{ fGCS } & $9-15$ & $21.5(11.8-28.9)$ & 0.13 & 13 & $4.6(3.2-7.7)$ & 0.10 & 14 & $11.5(10.0-14.5)$ & 0.000 & 16 \\
\hline & $3-8$ & $30.5(16.5-53.8)$ & & 30 & $8.4(3.9-10.7)$ & & 32 & $4.0(3.0-7.0)$ & & 33 \\
\hline \multirow{2}{*}{$\begin{array}{l}\text { Pupil reaction on the field } \\
\text { of the accident }\end{array}$} & Normal & $22.7(12.8-47.7)$ & 0.74 & 20 & $4.7(2.5-5.6)$ & 0.15 & 20 & $8.0(4.0-12.5)$ & 0.07 & 24 \\
\hline & Abnormal & $27.2(16.1-47.1)$ & & 19 & $5.2(2.7-7.3)$ & & 19 & $4.0(3.0-8.0)$ & & 21 \\
\hline \multirow[t]{2}{*}{ GCS14 } & $9-15$ & $21.6(13.3-38.9)$ & 0.54 & 23 & $5.3(3.8-8.9)$ & 0.16 & 25 & $7.5(3.0-11.0)$ & 0.31 & 26 \\
\hline & $3-8$ & $29.5(16.1-52.7)$ & & 20 & $8.3(5.5-11.3)$ & & 21 & $6.0(3.0-8.0)$ & & 23 \\
\hline \multirow[t]{2}{*}{ GOSE at 3 months } & $5-8$ & $21.2(15.3-61.1)$ & 0.72 & 4 & $4.7(2.9-7.0)$ & 0.34 & 4 & $7.0(3.3-10.5)$ & 0.94 & 4 \\
\hline & $1-4$ & $28.9(16.1-52.7)$ & & 27 & $7.2(3.3-10.1)$ & & 30 & $7.0(3.0-10.0)$ & & 33 \\
\hline \multirow[t]{2}{*}{ Mortality at 3 months } & Alive & $21.6(13.3-48.9)$ & 0.40 & 31 & $5.7(3.5-9.6)$ & 0.11 & 33 & $7.0(3.0-10.0)$ & 0.78 & 34 \\
\hline & Dead & $30.9(19.6-44.3)$ & & 12 & $8.3(6.0-12.3)$ & & 13 & $7.0(3.0-8.5)$ & & 15 \\
\hline \multirow[t]{2}{*}{ LOS $\geq 10$ days for survivors in ICU } & No & $20.6(9.8-31.0)$ & 0.14 & 17 & $4.0(3.2-7.6)$ & 0.06 & 18 & $9.0(5.5-11.5)$ & 0.02 & 19 \\
\hline & Yes & $27.2(16.5-55.2)$ & & 17 & $9.1(3.7-10.7)$ & & 16 & $5.0(3.0-8.0)$ & & 18 \\
\hline \multirow[t]{2}{*}{ LOS $\geq 10$ days or death in ICU } & No & $20.6(9.8-31.0)$ & 0.06 & 17 & $4.0(3.2-7.6)$ & 0.007 & 18 & $9.0(5.5-11.5)$ & 0.03 & 19 \\
\hline & Yes & $30.9(18.6-53.8)$ & & 26 & $8.9(5.4-11.3)$ & & 28 & $4.0(3.0-8.0)$ & & 30 \\
\hline \multirow{2}{*}{$\begin{array}{l}\text { LOS } \geq 17 \text { days for survivors in } \\
\text { acute hospital }\end{array}$} & No & $15.5(6.9-26.7)$ & 0.04 & 16 & $3.9(3.2-6.4)$ & 0.04 & 17 & $9.0(7.0-12.0)$ & 0.01 & 18 \\
\hline & Yes & $27.2(18.6-53.8)$ & & 17 & $8.8(4.0-10.1)$ & & 17 & $3.0(3.0-8.0)$ & & 18 \\
\hline
\end{tabular}

accident as compared to patients without edema, without SAH or with normal pupil reactions (Table 3).

Maximal early MMP-9 concentration, late c-Fn concentration and fGCS were similar in patients with a midline shift $\geq 5 \mathrm{~mm}$, with IVH or with a GOSE at 3 months $\leq 4$ as compared respectively to patients with a midline shift $<5 \mathrm{~mm}$, without IVH or with a GOSE at 3 months $>4$ (Table 3 ).

\section{Relationship between MMP-9, c-Fn, fGCS and secondary outcomes ICU LOS of survivors}

Statistically lower fGCS ( $p=0.02, n=37)$ as well as a trend toward higher maximal early MMP-9 concentration $(+32 \%, p=0.14, n=34)$ or late c-Fn concentration $(+127 \%, p=0.06, n=34)$ were observed in patients staying for 10 days or more in the ICU as compared to patients who were alive and who left the ICU before 10 days (Table 3 ).

\section{Death before 3 months}

A trend toward higher maximal late $\mathrm{c}$-Fn concentration was observed in patient who died before 3 months $(+46 \%$, $p=0.11, n=46)$ as compared to patients who survived. Maximal early MMP-9 concentration and fGCS were similar in patients who died or survived (Table 3).

\section{Consciousness at 14 days}

A trend toward higher maximal late c-Fn concentration was also observed in patients with a GCS at 14 days $\leq 8$ $(+57 \%, p=0.16, n=46)$ as compared to patients with a GCS at 14 days $>8$. Maximal early MMP-9 concentration and fGCS were similar in patients with a GCS at 14 days $\leq 8$ or a GCS at 14 days $>8$ (Table 3 ).

\section{GOSE at 3 months}

No relationship was observed between MMP-9, c-Fn concentrations or fGCS and the Glasgow Outcome Scale Extended at 3 months (Table 3). 


\section{Relationship between MMP-9, c-Fn, fGCS and the composite endpoint}

Statistically lower fGCS $(p=0.03, n=49)$ and higher maximal late c-Fn concentration $(+123 \%, p=0.007, n=46)$ as well as a strong trend toward higher maximal early MMP-9 concentration $(+50 \%, p=0.06, n=43)$ were observed in patients dying or staying for 10 days or more in the ICU as compared to patients who were alive and who left the ICU before 10 days (Table 3).

ROC curves for discriminating patients who died or stayed longer than 9 days in the ICU (Figure 3A) showed a slightly higher area under the curve (AUC) for maximal late $\mathrm{c}-\mathrm{Fn}$ concentration (AUC $=0.737$ ) than fGCS $($ AUC $=0.682)$ or maximal early MMP-9 concentration $($ AUC $=0.674)$. However, the ROC curves were not statistically different (bootstap test).

There was a 1.8 greater probability of dying or of staying longer than 9 days in the ICU for patients with a maximal late c-Fn concentration $\geq 7.7 \mu \mathrm{g} / \mathrm{ml}(\mathrm{OR}, 5.4$; 95\% CI, 1.4-20.8; $p=0.01$; sensitivity/specificity: $60.7 \%$ / $77.8 \%$, Figure $3 \mathrm{~B}$ ), and a 2.0 greater probability for patients with a maximal early MMP-9 $\geq 21.6 \mathrm{ng} / \mathrm{ml}$ (OR, 5.0; $95 \% \mathrm{CI}, 1.3-18.6 ; \mathrm{p}=0.02$; sensitivity/specificity: $73.1 \% / 64.7 \%$, Figure $3 \mathrm{~B}$ ). The risk of dying or of staying longer than 9 days in the ICU was 1.9 time higher for patients with a fGCS $\leq 8$ as compared to patients with a fGCS > 8 (OR, 4.4; 95\% CI, 1.2-15.8; $\mathrm{p}=0.02$; sensitivity/ specificity: $80.0 \% / 52.6 \%)$.

The association of c-Fn or MMP-9 with fGCS for predicting mortality or a LOS longer than 9 days in the ICU decreased dramatically the sensitivity of the tests (maximal late c-Fn concentration $\geq 7.7 \mu \mathrm{g} / \mathrm{ml}$ and $\mathrm{fGCS} \leq 8$ : OR, 5.0; 95\% CI, 1.2-20.8; $p=0.03$; sensitivity/specificity: $48.3 \% /$ $84.2 \%$; maximal early MMP-9 $\geq 21.6 \mathrm{ng} / \mathrm{ml}$ and fGCS $\leq 8$ : OR, 4.0; 95\% CI, 1.1-15.4; $p=0.04$; sensitivity/specificity: $53.6 \% / 77.8 \%)$.

\section{Discussion}

Our data confirm the initial raise of plasma MMP-9 concentration after TBI in humans as reported by other investigators based on animal models. To our knowledge, this is the first report of a raise of plasma c-Fn concentration in TBI patients and first observation of a temporal relationship between plasma MMP-9 concentration and plasma c-Fn concentration. Furthermore it is the first time that a correlation analysis is performed between MMP-9, c-Fn, fGCS and TBI patient outcome. MMP-9, c-Fn and fGCS have similar predictive values for the composite patient-relevant endpoint ICU LOS and death. In contrast, associating the blood markers with fGCS for predicting ICU LOS and death rendered the tests ineffective with sensitivities close to 0.5 .

In a rat TBI model, the local brain MMP-9 level was highest at $24 \mathrm{~h}$ after trauma with a second peak at 72
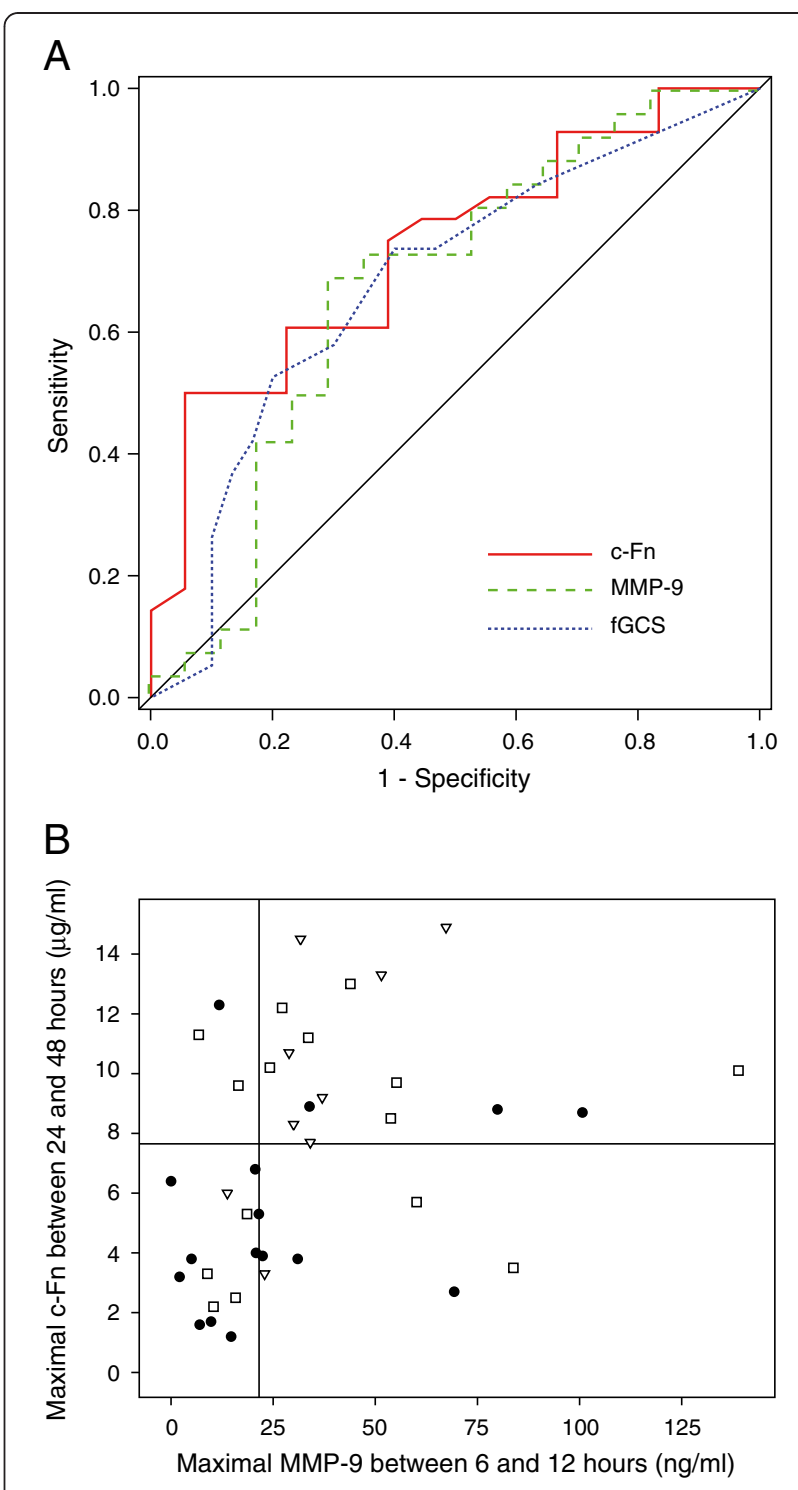

Figure 3 ROC curves and relationship between MMP-9 and c-Fn concentrations and ICU LOS or death. A: Roc curve analysis of maximal MMP-9 concentration between 6 and 12 hours, maximal c-Fn concentration] between 24 and 48 hours and fGCS for the prediction of ICU LOS $\geq 10$ days or death in the ICU. Plain line: maximal c-Fn concentration between 24 and 48 hours; dash line: maximal MMP-9 concentration between 6 and 12 hours; dot line: fGCS; diagonal line: reference line. B: Relationship between MMP-9 and C-Fn concentrations and ICU LOS or death. Maximal MMP-9 between 6 and 12 hours was plotted against maximal c-Fn concentrations between 24 and 48 hours. Horizontal line: $7.65 \mu \mathrm{g} / \mathrm{ml}$ threshold; vertical line: $21.55 \mathrm{ng} / \mathrm{ml}$ threshold; circles: survivors leaving the ICU before 10 days; squares: survivors leaving the ICU at 10 days or later; triangles: patients who died in the ICU.

hours [24]. In a second rat TBI model, the local brain ProMMP-9 (the latent form of MMP-9) was highest at $6 \mathrm{~h}$ and lower levels were observed at $24 \mathrm{~h}$ [25]. In a third rat TBI model, the local brain MMP-9 activity was highest at 24 hours [26]. In our patients, the maximal 
plasma MMP-9 levels were at 6 and 12 hours. This difference may be species-related or due to different trauma mechanisms.

Early MMP-9 increase may cause BBB degradation leading to later c-Fn release, therefore, a relationship between maximal early MMP-9 concentration and subsequent maximal c-Fn concentration is not surprising. This temporal profile of MMP-9 and c-Fn concentrations supports a role for MMP-9 in fibril degradation after TBI. Both MMP-9 and c-Fn concentrations tend to be higher in patients with brain oedema. The cause of MMP-9 increase after TBI has not been investigated in our study but could be related to inflammation and neutrophil activation $[41,42]$ after injury. Activated MMP-9 degrades c-Fn, which is released into circulation as a marker of clinical severity as suggested by the trend toward higher maximal c-Fn concentration between 24 and 48 hours in patients with a GCS at 14 days $\leq 8$ and in patients that died before 3 months.

The risk of longer ICU LOS ( $\geq 10$ days) for survivors or death in the ICU was statistically increased in patients with a maximal MMP-9 concentration equal of higher than $21.6 \mathrm{ng} / \mathrm{ml}$ between 6 and 12 hours after TBI or with a maximal c-Fn equal or higher than $7.7 \mu \mathrm{g} / \mathrm{ml}$ between 24 and 48 hours. A statistically significant relationship between this composite endpoint and fGCS equal or lower than 8 was also observed. Patients with severe TBI have two pattern of LOS in hospital: Nonsurvivors with a short median hospital LOS of 3 days and survivors with a long median hospital stay of 24 days [43]. ICU LOS is directly related to the clinical condition of the patients. MMP-9 and c-Fn concentration measurements might be more objective and reliable tools than fGCS for the prediction of the ICU LOS or death because the considerable inaccuracy in GCS scoring in daily practice [10].

Early prognostic factors of hospital LOS after severe TBI were rarely investigated but could have clinical implications. Apart the short LOS of patients with fatal injuries [43], post-traumatic sepsis and pneumonia were considered as risk factors for prolonged hospital LOS [44]. Early predictors such as MMP-9 and c-Fn may be useful for enhanced in-hospital health care resources planning and improved patient and family information. Furthermore, ICU LOS is a relevant predictor for rehabilitation LOS after traumatic brain injury underlying the desirability of improved hospital LOS prediction [45].

This study has several limitations. First, the significant relationship between early brain-derived biomarkers sampled in blood and the composite endpoint will not mean causality between the degree of TBI and patients' outcome. Second, inclusion criteria was not defined with the physiological instrument GCS, but with the anatomical instrument HAIS. This cohort of 49 patients had, therefore, included patients with different states of consciousness with a median fGCS 7 and median GCS 3 in the emergency department. The inclusion criteria of this study was based on the AIS trauma system to avoid biases related to clinical interventions and inter-rater variability [10]. Third, our results have to be considered as a proof-of-concept. In contrast to animal studies, patients with TBI have a heterogeneous brain injury pattern and different sizes of injuries with different quantity of release of biomarkers making relationship with clinical outcomes less evident. The absence of relationship for the component end points alone and the other secondary outcomes in our cohort of 49 patients will not exclude any association in a more homogeneous or larger population. Probably, a very high number of patients would be needed to test association for a single patientrelevant outcome. Composite endpoint provides evidence for a hypothesis with fewer patients, but may be criticised. However, there is a biological basis for our results: Brain edema, a major cause of secondary injury after TBI $[46,47]$, is partly due to MMP-9 activation and degradation of components of the basal lamina such as c-Fn, leading to blood-brain barrier disruption [20] and to severe TBI with prolonged ICU stay and death.

The clinical relevance of our results is actually limited despite an association between the biomarkers MMP-9 and c-Fn and a clinical composite endpoint. However, this clinical study has confirmed some postulated mechanisms in the early phase of TBI the first time in humans. Therefore, there is a potential that these early plasmatic biomarkers may predict patients' outcome. Validation of our results with other more homogenous and larger TBI populations is needed before clinical implementation may be considered.

\section{Conclusion}

In conclusion, the plasma biomarkers MMP-9 and c-Fn can be measured in the early phase after TBI and are predictive for the composite endpoint of ICU LOS in survivors and death but not for consciousness at 14 days nor outcome at 3 months.

\section{Competing interests \\ The authors declare that they have no competing interests.}

\section{Authors' contributions}

JCC and BW contributed to the conception of the study, to the acquisition and analysis of the data, and drafted the manuscript. MR participated in the acquisition of the data. NT and XR helped in statistical analysis, in

interpretation of the results and in the editing of the manuscript. JCS, KS and YG helped in interpretation of the results and in the editing of the manuscript. All authors have read and approved the final version of this manuscript.

\section{Acknowledgements}

This study was supported by the SUVA Foundation (BW), the BangerterRhyner Foundation (BW), the Geneva University Hospital Research \& 
Development fund (YG) and the Swiss National Science Foundation grant \#32003B-116774 (YG).

\begin{abstract}
Author details
${ }^{1}$ Geneva Neuroscience Center, University of Geneva, Geneva, Switzerland. ${ }^{2}$ Division of Intensive Care, University Hospitals of Geneva, Geneva, Switzerland. ${ }^{3}$ Division of Neurosurgery, University Hospitals of Geneva, Geneva, Switzerland. ${ }^{4}$ Division of Anaesthesiology, University Hospitals of Geneva, Geneva, Switzerland. ${ }^{5}$ Biomedical Proteomics Research Group, Department of Human Protein Sciences, University of Geneva Medical Center, Geneva, Switzerland. ${ }^{6}$ Centre Médical Universitaire, 1, rue Michel Servet, Genève $4 \mathrm{CH}-1211$, Switzerland.
\end{abstract}

Received: 31 August 2012 Accepted: 16 December 2012 Published: 18 December 2012

\section{References}

1. Olesen J, Gustavsson A, Svensson M, Wittchen HU, Jonsson B: The economic cost of brain disorders in Europe. Eur J Neurol 2012, 19:155-162.

2. van Velzen JM, van Bennekom CA, Edelaar MJ, Sluiter JK, Frings-Dresen $\mathrm{MH}$ How many people return to work after acquired brain injury?: a systematic review. Brain Inj 2009, 23:473-488.

3. Bouillon B, Raum M, Fach H, Buchheister B, Lefering R, Menzel J, Klug N: The incidence and outcome of severe brain trauma - Design and first results of an epidemiological study in an urban area. Restor Neurol Neurosci 1999, 14:85-92.

4. Masson F, Thicoipe M, Aye P, Mokni T, Senjean P, Schmitt V, Dessalles PH, Cazaugade M, Labadens P, Injur AGSB: Epidemiology of severe brain injuries: a prospective population-based study. J Trauma 2001, 51:481-489.

5. Andelic N, Anke A, Skandsen T, Sigurdardottir S, Sandhaug M, Ader T, Roe C Incidence of hospital-admitted severe traumatic brain injury and inhospital fatality in Norway: a national cohort study. Neuroepidemiology 2012, 38:259-267.

6. Andriessen TM, Horn J, Franschman G, van der Naalt J, Haitsma I, Jacobs B, Steyerberg EW, Vos PE: Epidemiology, severity classification, and outcome of moderate and severe traumatic brain injury: a prospective multicenter study. J Neurotrauma 2011, 28:2019-2031.

7. Murray CJ, Lopez AD: Mortality by cause for eight regions of the world: global burden of disease study. Lancet 1997, 349:1269-1276.

8. von Elm E, Osterwalder JJ, Graber C, Schoettker P, Stocker R, Zangger P, Vuadens $P$, Egger $M$, Walder $B$ : Severe traumatic brain injury in Switzerland - feasibility and first results of a cohort study. Swiss Med Wkly 2008, 138:327-334.

9. Roozenbeek B, Chiu YL, Lingsma HF, Gerber LM, Steyerberg EW, Ghajar J, Maas Al: Predicting 14-day mortality after severe traumatic brain injury: application of the IMPACT models in the brain trauma foundation TBI$\operatorname{trac}(\mathrm{R})$ New York State database. J Neurotrauma 2012, 29:1306-1312.

10. Zuercher M, Ummenhofer W, Baltussen A, Walder B: The use of Glasgow Coma Scale in injury assessment: a critical review. Brain Inj 2009, 23:371-384.

11. Bohmer AE, Oses JP, Schmidt AP, Peron CS, Krebs CL, Oppitz PP, D'Avila TT, Souza DO, Portela LV, Stefani MA: Neuron-specific enolase, S100B, and glial fibrillary acidic protein levels as outcome predictors in patients with severe traumatic brain injury. Neurosurgery 2011, 68:1624-1630. discussion 1630-1621.

12. Dalla Libera AL, Regner A, de Paoli J, Centenaro L, Martins TT, Simon D: IL-6 polymorphism associated with fatal outcome in patients with severe traumatic brain injury. Brain Inj 2011, 25:365-369.

13. Hergenroeder GW, Moore AN, McCoy JP Jr, Samsel L, Ward NH 3rd, Clifton GL, Dash PK: Serum IL-6: a candidate biomarker for intracranial pressure elevation following isolated traumatic brain injury. J Neuroinflammation 2010, 7:19.

14. Lin Z, Han M, Li H, Luo H, Zhang Y, Luo W: Soluble vascular adhesion protein-1: decreased activity in the plasma of trauma victims and predictive marker for severity of traumatic brain injury. Clin Chim Acto 2011, 412:1678-1682.

15. McKeating EG, Andrews PJ, Mascia L: The relationship of soluble adhesion molecule concentrations in systemic and jugular venous serum to injury severity and outcome after traumatic brain injury. Anesth Analg 1998, 86:759-765.

16. Mondello S, Gabrielli A, Catani S, D'Ippolito M, Jeromin A, Ciaramella A, Bossu P, Schmid K, Tortella F, Wang KK, et al: Increased levels of serum
MAP-2 at 6-months correlate with improved outcome in survivors of severe traumatic brain injury. Brain Inj 2012, 26:1629-1635.

17. Mondello S, Linnet A, Buki A, Robicsek S, Gabrielli A, Tepas J, Papa L, Brophy GM, Tortella F, Hayes RL, Wang KK: Clinical utility of serum levels of ubiquitin C-terminal hydrolase as a biomarker for severe traumatic brain injury. Neurosurgery 2012, 70:666-675.

18. Sen J, Belli A: S100B in neuropathologic states: the CRP of the brain? J Neurosci Res 2007, 85:1373-1380.

19. Vos PE, Jacobs B, Andriessen TM, Lamers KJ, Borm GF, Beems T, Edwards M, Rosmalen CF, Vissers JL: GFAP and S100B are biomarkers of traumatic brain injury: an observational cohort study. Neurology 2010, 75:1786-1793.

20. Gasche Y, Soccal PM, Kanemitsu M, Copin JC: Matrix metalloproteinases and diseases of the central nervous system with a special emphasis on ischemic brain. Front Biosci 2006, 11:1289-1301.

21. Gidday JM, Gasche YG, Copin JC, Shah AR, Perez RS, Shapiro SD, Chan PH, Park TS: Leukocyte-derived matrix metalloproteinase- 9 mediates bloodbrain barrier breakdown and is proinflammatory after transient focal cerebral ischemia. Am J Physiol Heart Circ Physiol 2005, 289:H558-568.

22. Copin JC, Merlani P, Sugawara T, Chan PH, Gasche Y: Delayed matrix metalloproteinase inhibition reduces intracerebral hemorrhage after embolic stroke in rats. Exp Neurol 2008, 213:196-201.

23. Rosell A, Cuadrado E, Ortega-Aznar A, Hernandez-Guillamon M, Lo EH, Montaner J: MMP-9-Positive neutrophil infiltration is associated to bloodbrain barrier breakdown and basal lamina type IV collagen degradation during hemorrhagic transformation after human ischemic stroke. Stroke 2008, 39:1121-1126.

24. Jia F, Pan YH, Mao Q, Liang YM, Jiang JY: Matrix metalloproteinase-9 expression and protein levels after fluid percussion injury in rats: the effect of injury severity and brain temperature. J Neurotrauma 2010, 27:1059-1068.

25. Lescot T, Fulla-Oller L, Palmier B, Po C, Beziaud T, Puybasset L, Plotkine M, Gillet B, Meric P, Marchand-Leroux C: Effect of Acute Poly(ADP-Ribose) Polymerase Inhibition by $3-A B$ on Blood-brain Barrier Permeability and Edema Formation after Focal Traumatic Brain Injury in Rats. J Neurotrauma 2010, 27:1069-1079.

26. Truettner JS, Alonso OF, Dalton Dietrich W: Influence of therapeutic hypothermia on matrix metalloproteinase activity after traumatic brain injury in rats. J Cereb Blood Flow Metab 2005, 25:1505-1516.

27. Wang XY, Jung JC, Asahi M, Chwang W, Russo L, Moskowitz MA, Dixon CE, Fini ME, Lo EH: Effects of matrix metalloproteinase-9 gene knock-out on morphological and motor outcomes after traumatic brain injury. J Neurosci 2000, 20:7037-7042.

28. Tejima E, Guo SZ, Murata Y, Arai K, Lok J, van Leyen K, Rosell A, Wang XY, Lo EH: Neuroprotective Effects of Overexpressing Tissue Inhibitor of Metalloproteinase TIMP-1. J Neurotrauma 2009, 26:1935-1941.

29. Grossetete M, Phelps J, Arko L, Yonas H, Rosenberg GA: Elevation of matrix metalloproteinases 3 and 9 in cerebrospinal fluid and blood in patients with severe traumatic brain injury. Neurosurgery 2009, 65:702-708.

30. Suehiro E, Fujisawa H, Akimura T, Ishihara H, Kajiwara K, Kato S, Fujii M, Yamashita S, Maekawa T, Suzuki M: Increased matrix metalloproteinase-9 in blood in association with activation of interleukin- 6 after traumatic brain injury: Influence of hypothermic therapy. J Neurotrauma 2004, 21:1706-1711.

31. Vilalta A, Sahuquillo J, Rosell A, Poca MA, Riveiro M, Montaner J: Moderate and severe traumatic brain injury induce early overexpression of systemic and brain gelatinases. Intensive Care Med 2008, 34:1384-1392.

32. Singh P, Carraher C, Schwarzbauer JE: Assembly of fibronectin extracellular matrix. Annu Rev Cell Dev Biol 2010, 26:397-419.

33. White ES, Baralle FE, Muro AF: New insights into form and function of fibronectin splice variants. J Pathol 2008, 216:1-14.

34. Astrof $\mathrm{S}$, Hynes RO: Fibronectins in vascular morphogenesis. Angiogenesis 2009, 12:165-175.

35. Peters JH, Loredo GA, Chen G, Maunder R, Hahn TJ, Willits NH, Hynes RO: Plasma levels of fibronectin bearing the alternatively spliced EllIB segment are increased after major trauma. J Lab Clin Med 2003, 141:401-410.

36. Castellanos M, Sobrino T, Millan M, Garcia M, Arenillas J, Nombela F, Brea D, Perez De La Ossa N, Serena J, Vivancos J, et al: Serum cellular fibronectin and matrix metalloproteinase- 9 as screening biomarkers for the prediction of parenchymal hematoma after thrombolytic therapy in acute ischemic stroke. A multicenter confirmatory study. Stroke 2007, 38:1855-1859 
37. American Association for Automotive Medicine: Committee on injury scaling. In The abbreviated injury scale 1990 revision-update 98.1980 Revision. Des Plains, IL: American Association for Automotive Medicine; 1998.

38. Wilson JT, Pettigrew LE, Teasdale GM: Structured interviews for the Glasgow Outcome Scale and the extended Glasgow Outcome Scale: guidelines for their use. J Neurotrauma 1998, 15:573-585.

39. Perel P, Arango M, Clayton T, Edwards P, Komolafe E, Poccock S, Roberts I, Shakur $\mathrm{H}$, Steyerberg E, Yutthakasemsunt S: Predicting outcome after traumatic brain injury: practical prognostic models based on large cohort of international patients. BMJ 2008, 336:425-429.

40. Robin X, Turck N, Hainard A, Tiberti N, Lisacek F, Sanchez JC, Muller M: pROC: an open-source package for $\mathrm{R}$ and $\mathrm{S}+$ to analyze and compare ROC curves. BMC Bioinforma 2011, 12:77.

41. Scholz M, Cinatl J, Schadel-Hopfner M, Windolf J: Neutrophils and the blood-brain barrier dysfunction after trauma. Med Res Rev 2007, 27:401-416.

42. Vecil GG, Larsen PH, Corley SM, Herx LM, Besson A, Goodyer CG, Yong WW: Interleukin-1 is a key regulator of matrix metalloproteinase-9 expression in human neurons in culture and following mouse brain trauma in vivo. J Neurosci Res 2000, 61:212-224.

43. Hyam JA, Welch CA, Harrison DA, Menon DK: Case mix, outcomes and comparison of risk prediction models for admissions to adult, general and specialist critical care units for head injury: a secondary analysis of the ICNARC Case Mix Programme Database. Crit Care 2006, 10(Suppl 2):S2.

44. Rondina C, Videtta W, Petroni G, Lujan S, Schoon P, Mori LB, Matkovich J, Carney N, Chesnut R: Mortality and morbidity from moderate to severe traumatic brain injury in Argentina. J Head Trauma Rehabil 2005, 20:368-376.

45. Arango-Lasprilla JC, Ketchum JM, Cifu D, Hammond F, Castillo C, Nicholls E, Watanabe T, Lequerica A, Deng X: Predictors of extended rehabilitation length of stay after traumatic brain injury. Arch Phys Med Rehabil 2010, 91:1495-1504.

46. Ghajar J: Traumatic brain injury. Lancet 2000, 356:923-929.

47. Donkin JJ, Vink R: Mechanisms of cerebral edema in traumatic brain injury: therapeutic developments. Curr Opin Neurol 2010, 23:293-299.

doi:10.1186/1757-7241-20-83

Cite this article as: Copin et al: Matrix metalloproteinase 9 and cellular fibronectin plasma concentrations are predictors of the composite endpoint of length of stay and death in the intensive care unit after severe traumatic brain injury. Scandinavian Journal of Trauma,

Resuscitation and Emergency Medicine 2012 20:83.

\section{Submit your next manuscript to BioMed Central and take full advantage of:}

- Convenient online submission

- Thorough peer review

- No space constraints or color figure charges

- Immediate publication on acceptance

- Inclusion in PubMed, CAS, Scopus and Google Scholar

- Research which is freely available for redistribution
C Biomed Central 